\title{
Método para mensuração das angulações e incli- nações das coroas dentárias utilizando modelos de gesso
}

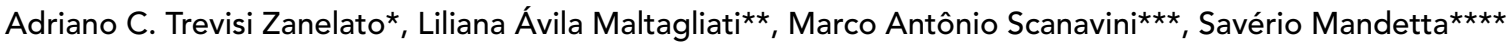

\begin{abstract}
Resumo
Este presente estudo teve por finalidade apresentar o desenvolvimento de um dispositivo especialmente projetado para mensurar as angulações e inclinações das coroas dentárias. Tal dispositivo foi utilizado em uma amostra de 60 indivíduos, na faixa etária de 12 a 21 anos, de ambos os gêneros. Os indivíduos apresentavam oclusão normal e nunca haviam sido submetidos a qualquer tipo de intervenção ortodôntica. Sendo assim, a partir desta amostra, estabeleceram-se os valores médios das angulações e inclinações das coroas dentárias para indivíduos brasileiros.
\end{abstract}

Palavras-chave: Angulação. Inclinação. Coroa dentária.

\section{INTRODUÇÃO}

Um trabalho pioneiro, que mudou a história da Ortodontia, indubitavelmente foi o de Lawrence F. Andrews ${ }^{1}$ (1970), que desenvolveu o primeiro aparelho ortodôntico totalmente pré-ajustado (Straight wire), incorporando aos braquetes informações referentes à angulação e à inclinação das coroas dentárias e colocando nesses, também, variações de espessuras, que eliminassem as dobras de primeira, segunda e terceira ordens, até então necessárias para o desenvolvimento dos tratamentos ortodônticos. Essas inclinações e angulações propostas por Andrews partiram de um trabalho realizado em 120 modelos de gesso de oclusão normal. A metodologia aplicada foi simples, com utilização de uma placa representativa do plano oclusal e de um transferidor modificado. Embora tenha sido um trabalho extraordinário, sendo hoje um dos clássicos da literatura, o trabalho de Andrews foi aplicado a uma única amostra de indivíduos norte-americanos. Ao tentarmos reproduzir sua metodologia, observamos que, embora prática e de fácil utilização, não conseguimos precisão no posicionamento das réguas e transferidor, criando dúvidas e alta variabilidade de resultados. Por esse motivo, idealizamos uma alteração na metodologia proposta, para que pudéssemos realizar um trabalho científico, em que o principal objetivo foi determinar a angulação e a inclinação das coroas dentárias, analogamente ao trabalho de Andrews, porém em uma amostra de adolescentes brasileiros, leucodermas, com oclusão normal natural.

* Mestrando em Ortodontia pela UMESP.

* Professora Titular da Faculdade de Odontologia da UMESP, Coordenadora do Curso de Especialização em Ortodontia da UMESP.

Professor Titular da Faculdade de Odontologia da UMESP, Coordenador do Programa de Pós-Graduação, área de concentração Ortodontia da UMESP.

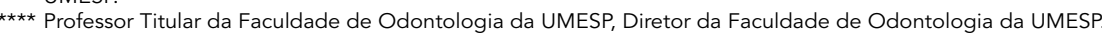




\section{REVISÃO DE LITERATURA}

Até o final do século XIX, a Ortodontia seguiu de maneira bastante precária, com "aparelhos ortodônticos" feitos à mão, dificultando a padronização e os procedimentos de movimentação dentária, comprometendo sobremaneira os resultados possíveis. Essas dificuldades levaram Edward H. Angle, em 1887, a criar o Sistema Angle, que serviu de base filosófica para a introdução, em 1928, do aparelho Edgewise ${ }^{5}$. No ano de 1887, Angle desenvolveu o primeiro braquete, um tubo de metal soldado verticalmente à banda metálica ${ }^{5}$. Esse sistema mostrou-se deficiente em alguns tipos de movimentos dentários, principalmente no controle do movimento de translação, o que o levou a desenvolver um novo aparelho, tipo pino e tubo. Foi o primeiro aparelho a realizar o movimento de raiz, mas as dificuldades de manipulação tornaram-no inviável. Em 1915, Angle idealizou o aparelho com "arco cinta". Esse aparelho destacava-se por apresentar a canaleta na posição vertical. Após muita experiências e alguns "insucessos", Angle resolveu mudar radicalmente o aparelho, colocando a canaleta no centro e na horizontal, tornando-o mais preciso e eficiente, principalmente no controle de tor$q^{2} e^{5}$. Esse novo sistema de braquete deu origem ao aparelho Edgewise, desenvolvido em 1928. A evolução seguia com o objetivo de transferir, para os braquetes, recursos que simplificassem o trabalho dos ortodontistas. Então, Holdaway ${ }^{3}$, em 1952, promoveu a primeira modificação, uma leve angulação, visando substituir as dobras de segunda ordem, nos casos de preparo de ancoragem. Jarabak ${ }^{4}$, em 1960, utilizou braquetes angulados em dois planos no espaço, a angulação mesiodistal preconizada por Holdaway ${ }^{3}$ e a angulação na canaleta dos braquetes, que tornaram a mecânica de terceira ordem possível com o emprego de arcos retangulares. As várias inovações e modificações no aparelho Edgewise padrão culminaram com o surgimento do primeiro aparelho pré-ajustado (Straight wire), idealizado por Andrews ${ }^{1}$.
Esse novo sistema de braquete apresentou inovações que foram capazes de substituir as dobras de primeira, segunda e terceira ordens. Para o novo aparelho, foi desenvolvida uma pesquisa, em um universo de 1.988 modelos, onde foram selecionados 120 casos de oclusão normal. O trabalho resumiu-se na determinação da área do braquete de cada tipo de dente e considerações das coroas dentárias, tais como angulação, inclinação, compensação do molar superior, contorno horizontal, proeminência vestibular e profundidade da curva de Spee. Para a determinação das medidas de angulação e inclinação das coroas dentárias e da compensação do molar superior, foi desenvolvido por Andrews um transferidor com braço de leitura ajustável (Fig. 1A) e dois gabaritos de plástico rígido aliviados na área dos caninos (Fig. 1B). Esses gabaritos foram usados para representar o plano oclusal dos modelos. Nos modelos de gesso, foram marcados o longo eixo vestibular da coroa clínica (EVCC) e o ponto médio do eixo vestibular (EV), que serviram de referências para a realização das medidas. $\mathrm{O}$ procedimento de medição utilizado por Andrews está detalhadamente descrito no capítulo 2 do livro Straight-wire: the concept and appliancel. As médias das angulações e inclinações de cada coroa dentária, encontradas no seu trabalho encontram-se nos quadros 1 e 2 .

\begin{tabular}{cccccccc}
\hline Dente & $\mathbf{1}$ & $\mathbf{2}$ & $\mathbf{3}$ & $\mathbf{4}$ & $\mathbf{5}$ & $\mathbf{6}$ & $\mathbf{7}$ \\
Angulação & $3,59^{\circ}$ & $8,04^{\circ}$ & $8,40^{\circ}$ & $2,65^{\circ}$ & $2,82^{\circ}$ & $5,73^{\circ}$ & $0,39^{\circ}$ \\
Inclinação & $6,11^{\circ}$ & $4,42^{\circ}$ & $-7,25^{\circ}$ & $-8,47$ & $-8,78^{\circ}$ & $-11,53^{\circ}$ & $-8,10^{\circ}$ \\
\hline
\end{tabular}

Quadro 1 - Angulações e inclinações dentárias para os dentes superiores.

\begin{tabular}{cccccccc}
\hline Dente & $\mathbf{1}$ & $\mathbf{2}$ & $\mathbf{3}$ & $\mathbf{4}$ & $\mathbf{5}$ & $\mathbf{6}$ & $\mathbf{7}$ \\
Angulação & $0,53^{\circ}$ & $0,38^{\circ}$ & $2,48^{\circ}$ & $1,28^{\circ}$ & $1,54^{\circ}$ & $2,03^{\circ}$ & $2,94^{\circ}$ \\
Inclinação & $-1,71^{\circ}$ & $-3,24^{\circ}$ & $-12,73^{\circ}$ & $-18,95^{\circ}$ & $-23,63^{\circ}$ & $-30,67^{\circ}$ & $-36,03^{\circ}$ \\
\hline
\end{tabular}

Quadro 2 - Angulações e Inclinações dentárias para os dentes inferiores. 


\section{Desenvolvimento do dispositivo}

O dispositivo foi desenvolvido com a finalidade de obter as medidas de angulação e inclinação das coroas dentárias, para a elaboração de uma Dissertação de Mestrado na Faculdade de Odontologia da UMESP. Para a realização desse trabalho, nos propusemos a desenvolver um dispositivo nunca antes utilizado em outras pesquisas. Trabalhamos conjuntamente com uma aluna do curso de graduação da Faculdade de Engenharia da Escola Politécnica da Universidade de São Paulo (USP), para o desenvolvimento desse dispositivo capaz de realizar a pesquisa.

\section{Descrição do dispositivo}

O dispositivo desenvolvido tem como elemento central um par de engrenagens-parafusos-sem-fim (Fig. 2). A engrenagem tem 360 dentes, representando cada dente uma unidade de grau (Fig. 3A). O parafuso sem-fim é responsável pelo acionamento controlado do sistema (Fig. 3B). Uma mesa em $\mathrm{L}$, onde o modelo é fixado, une-se rigidamente ao elemento central através de um eixo. A base da mesa é a referência móvel do sistema, enquanto o chão é a referência fixa e ambos foram calibrados para estarem paralelos (Fig. 2). Lateralmente à mesa que suporta o dispositivo foi colocada uma haste em forma de cruz, posicionada perpendicular à mesa em $\mathrm{L}$ e, logicamente, perpendicular ao solo (Fig. 4). A haste é responsável pelas medições das

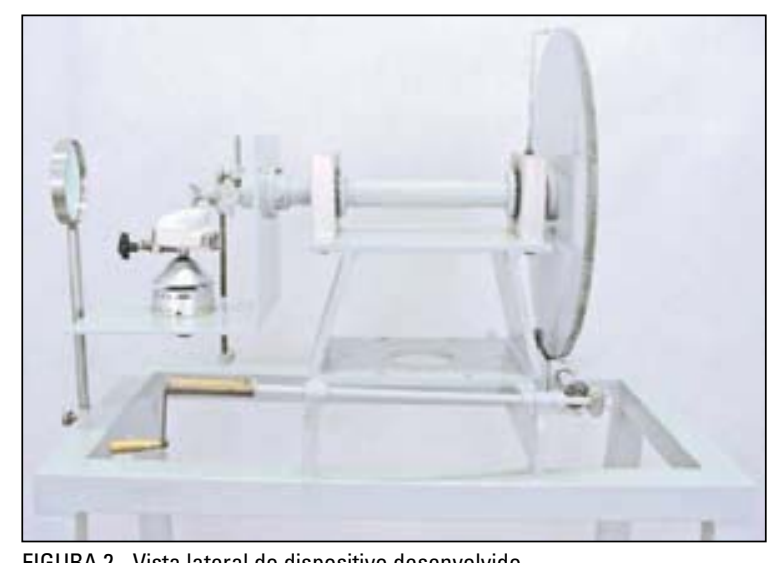

FIGURA 2 - Vista lateral do dispositivo desenvolvido.

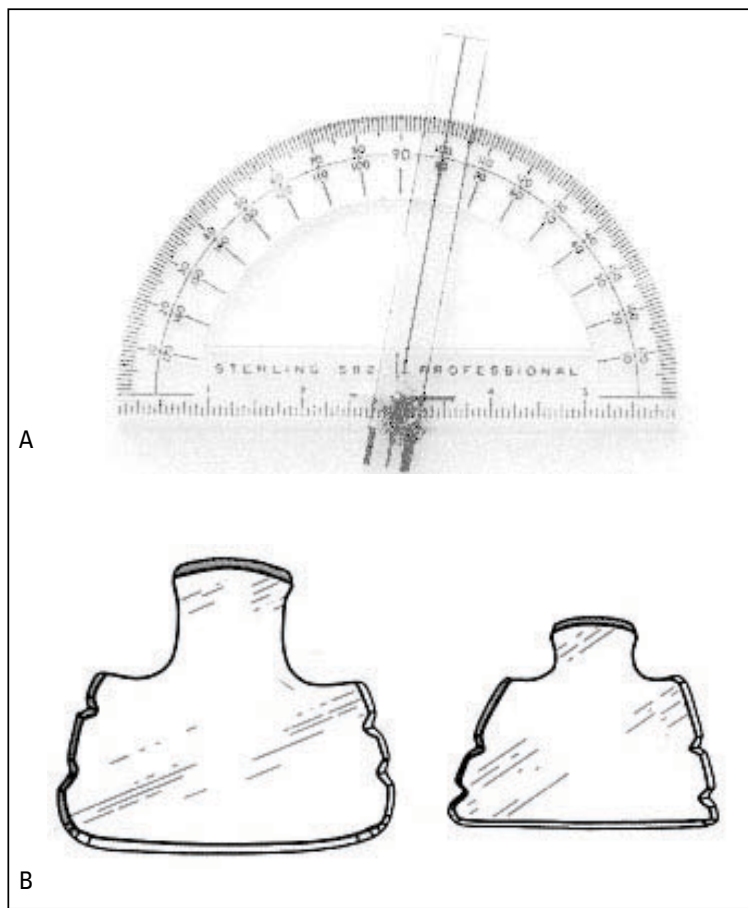

FIGURA 1 - A) Transferidor utilizado por Andrews para a medição da angulação e inclinação da coroa dentária. B) Gabarito utilizado por Andrews para representar o plano oclusal. FONTE: ANDREWS'.

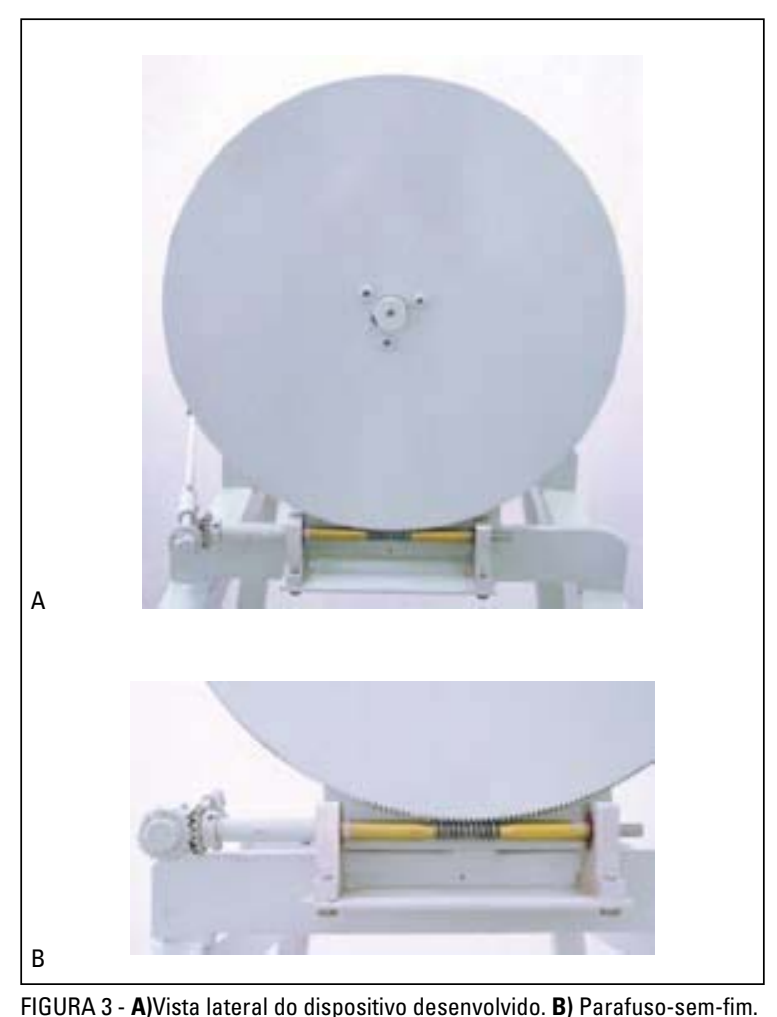

FIGURA 3 - A)Vista lateral do dispositivo desenvolvido. B) Parafuso-sem-fim. 


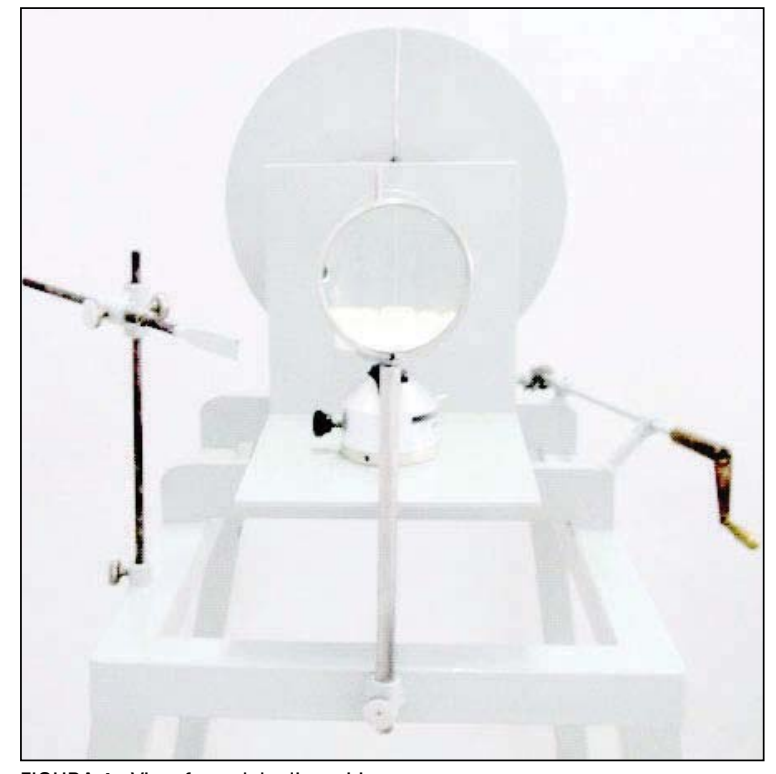

FIGURA 4 - Vista frontal do dispositivo. inclinações das coroas dentárias. Para a realização das medidas de angulações das coroas dentárias, foi instalada uma lente de aumento, com um risco central (Fig. 4). Essa lente de aumento foi posicionada na região anterior do dispositivo, de maneira que o risco central da lente de aumento fosse posicionado perpendicular à base da mesa em L.

\section{Calibração do dispositivo}

O dispositivo foi calibrado para permanecer paralelo ao solo, graças ao uso de um nível apoiado em várias partes do dispositivo (Fig. 5B), confirmando, realmente, a posição de paralelismo com o solo. A base do dispositivo apresenta pés giratórios, o que facilita o procedimento (Fig. 5A). O segundo passo na calibração do dispositivo foi

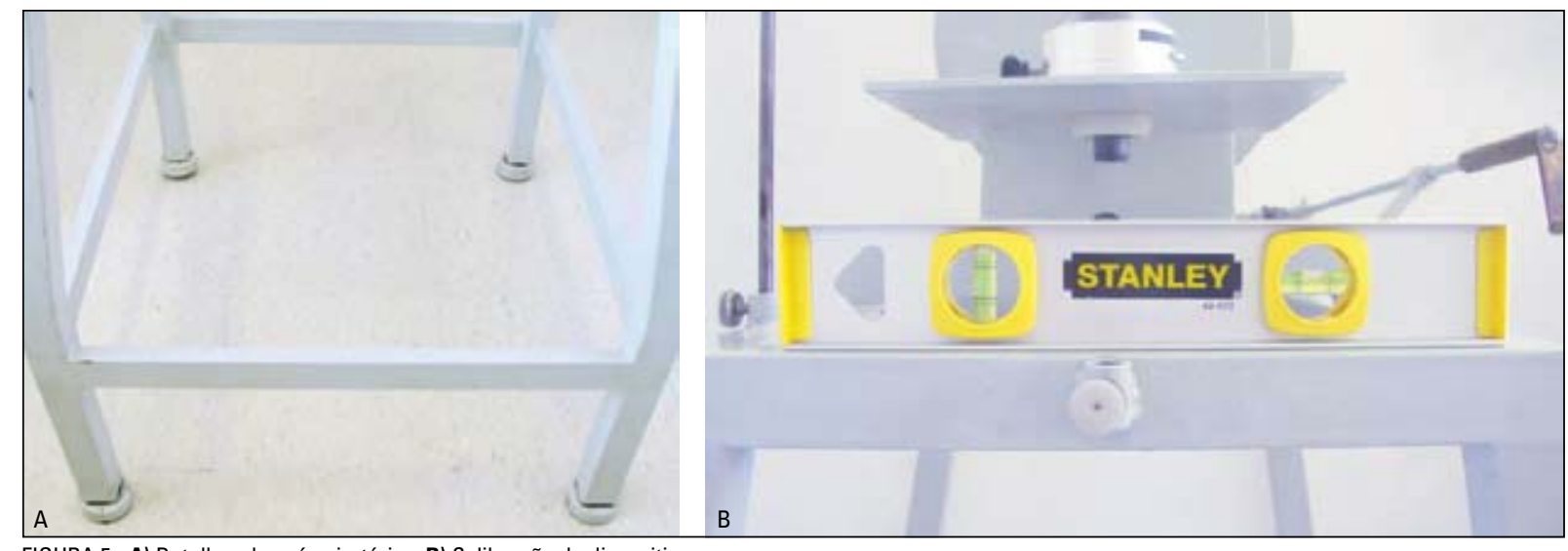

FIGURA 5 - A) Detalhes dos pés giratórios. B) Calibração do dispositivo.

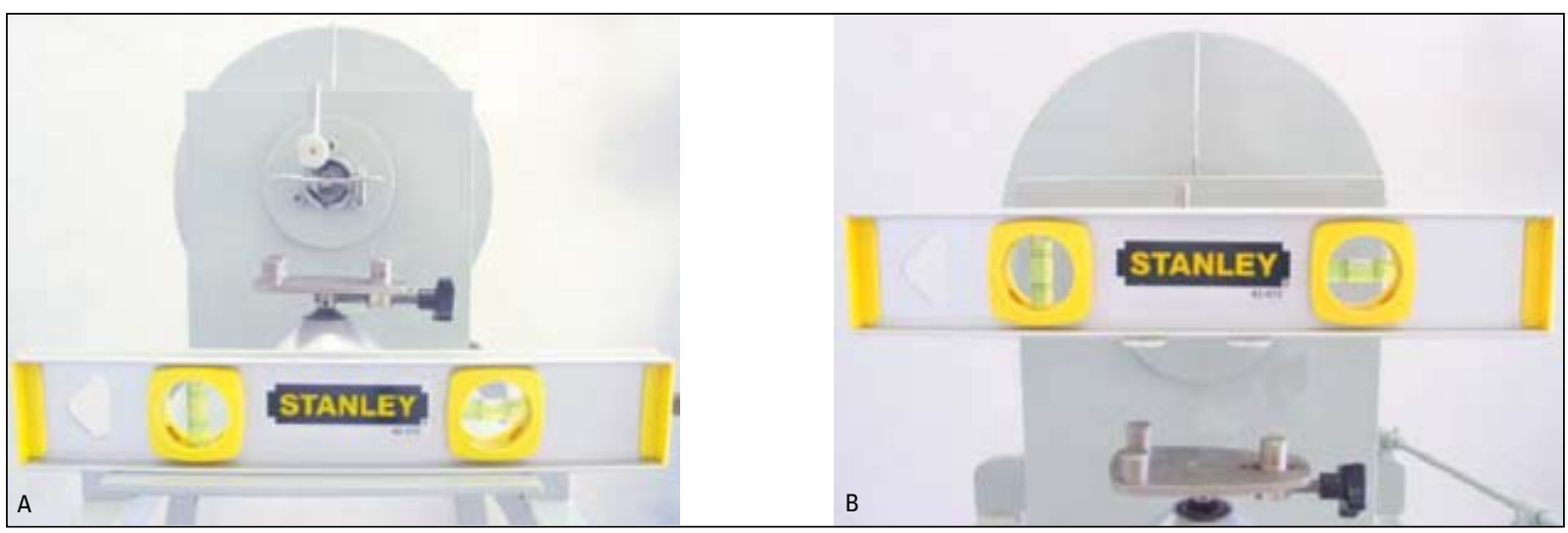

FIGURA 6 - A) Base da mesa em L paralela ao solo. B) Garfo posicionador do plano oclusal. 


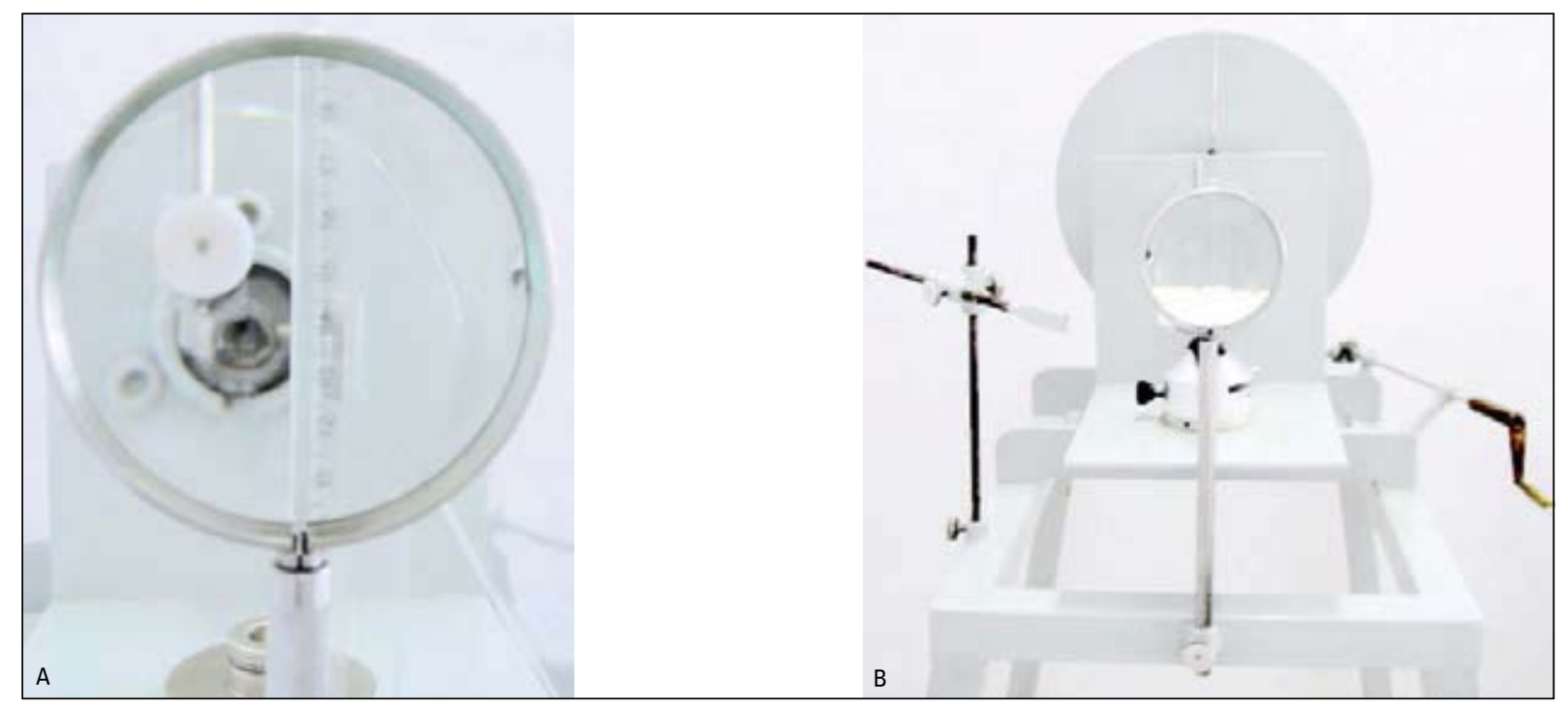

FIGURA 7 - A) Calibração da lente de aumento. B) Modelo posicionado para a medição da angulação da coroa dentária.

posicionar a mesa em L, que se situa do lado oposto à roda de 360 dentes (Fig. 2), paralelo à mesa que suporta o dispositivo e, automaticamente, paralelo ao solo. Estando a base da mesa em L paralela ao solo, definiu-se o ponto zero na roda de 360 dentes (Fig. 6A). O garfo, que é semelhante ao garfo de um articulador semi-ajustado, foi indiretamente calibrado, por estar fixo à mesa em L (Fig. 6B), tendo a função de posicionar o plano oclusal do modelo paralelo ao solo.

\section{Calibração da lente de aumento}

No centro da lente de aumento, utilizada para as medições da angulação das coroas dentárias, foi realizado um risco central (Fig. 7B), posicionado perpendicular ao solo. Para a calibragem, foi utilizado um esquadro (Fig. 7A), que foi colocado paralelo à base da mesa em $\mathrm{L}$, ajustando o risco central da lente de aumento de forma a coincidir com a haste perpendicular do esquadro.

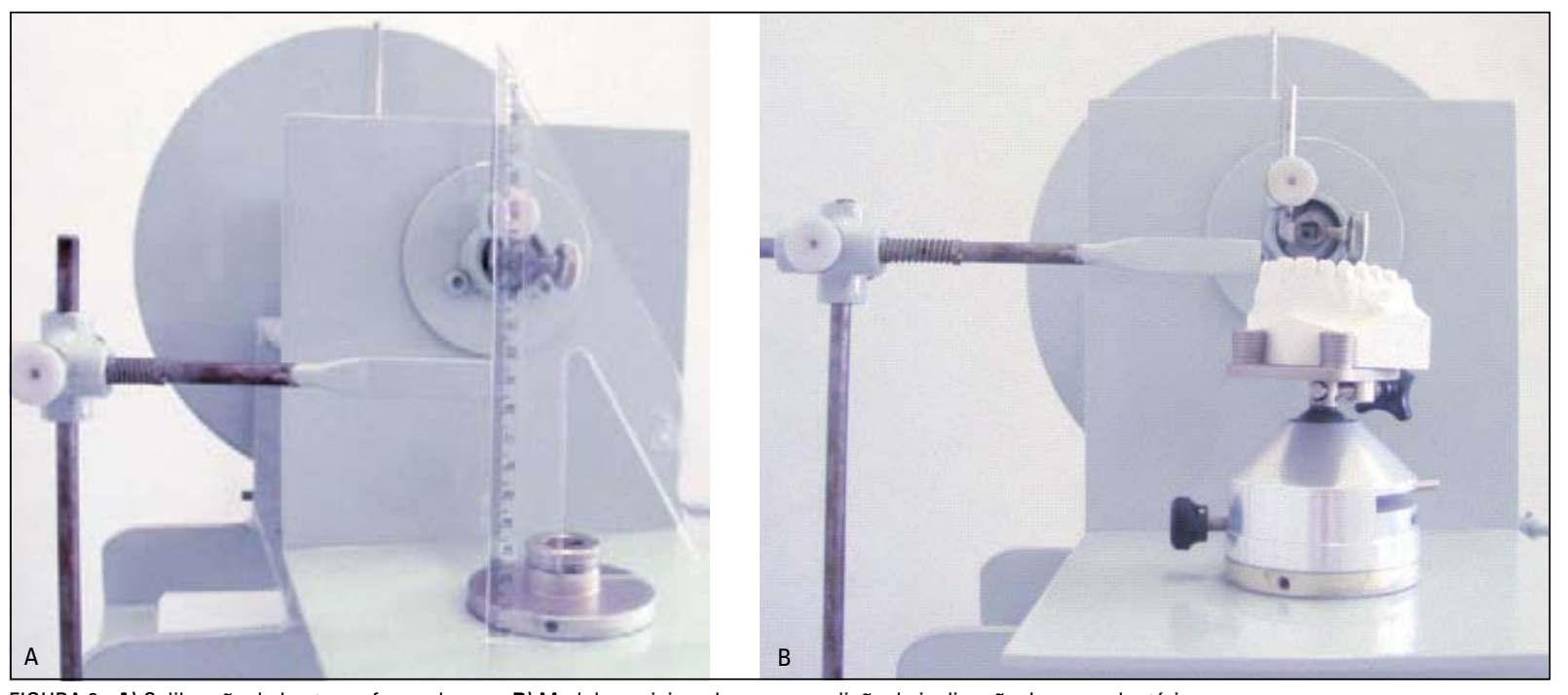

FIGURA 8 - A) Calibração da haste em forma de cruz. B) Modelo posicionado para a medição da inclinação da coroa dentária. 


\section{Calibração da haste em forma de cruz}

A haste lateral em forma de cruz do dispositivo, utilizada para medir a inclinação das coroas dentárias (Fig. 8B), foi ajustada de modo que sua ponta, que fica em contato com os dentes do modelo de gesso, estivesse perpendicular ao solo. $\mathrm{O}$ ajuste também foi realizado com o auxílio de um esquadro, apoiado na mesa em $\mathrm{L}$, de forma que a ponta da haste ficasse paralela ao esquadro (Fig. 8A).

\section{Fixação do modelo no dispositivo}

$\mathrm{O}$ modelo foi fixado à mesa em L por meio de um suporte articulado esfericamente (Fig. 9B). Assim podendo ser movimentado em todas as direções até estar com o plano oclusal paralelo à mesa em L. O paralelismo do plano oclusal com a mesa em L deu-se com o auxílio de um garfo, semelhante ao garfo do articulador semiajustável, fixado na parede vertical da mesa em L, dotado de movi-

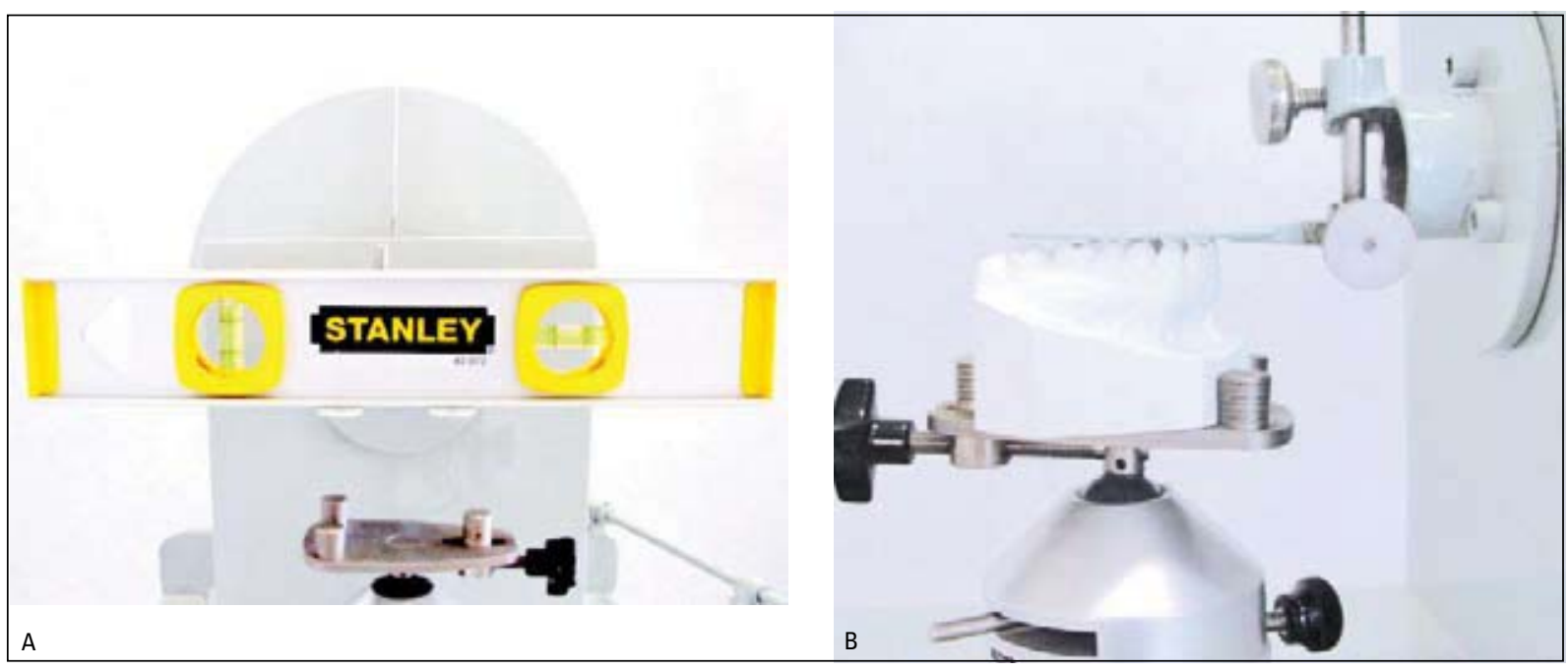

FIGURA 9 - A) Garfo do dispositivo calibrado. B) Modelo do gesso posicionado.

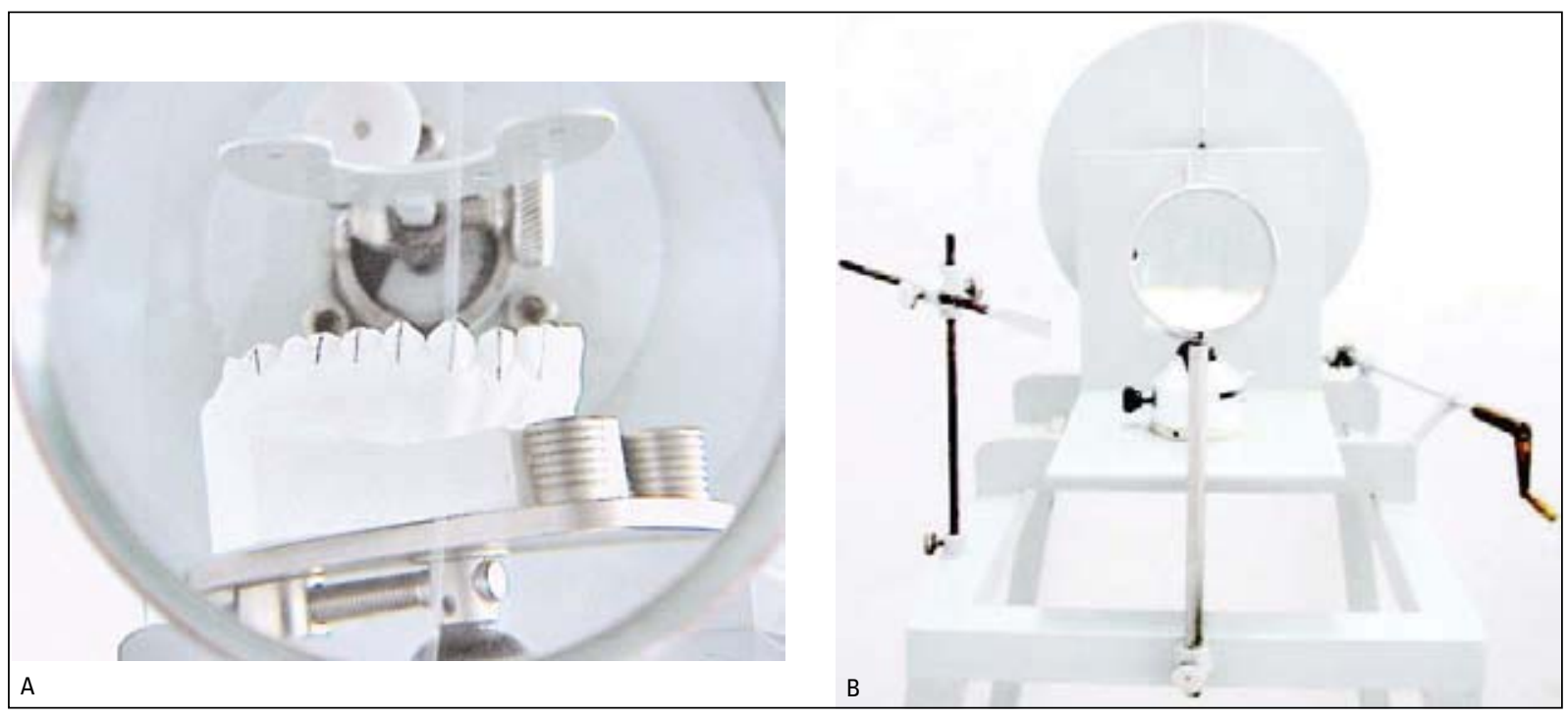

FIGURA 10 - A) Longo eixo da coroa dentária paralelo ao risco central da lente de aumento. B) Vista do dispositivo. 
mento vertical guiado. Junto com a mesa em L, o garfo também foi calibrado (Fig. 9A).

\section{Medição da angulação dentária}

Para a medição da angulação das coroas dentárias, o instrumento utilizado foi a lente de aumento. Essa lente, como já explicado, está fixada perpendicularmente à referência fixa e localizada na parte frontal do dispositivo (Fig. 10B). A referência para essa medição é o encontro do risco central da lente de aumento com o longo eixo da coroa de cada elemento dentário (Fig.10A).

\section{Procedimento de medição da angulação dentária}

Nos modelos de gesso, foi marcado, com uma lapiseira de $0,5 \mathrm{~mm}$, o longo eixo da coroa de cada elemento dentário ou, segundo Andrews, o eixo vestibular da coroa clínica (EVCC). Esse procedimento serviu como referência para a determinação da angulação de cada coroa dentária. Com o modelo corretamente posicionado e fixado, rotacionamos a mesa em $\mathrm{L}$ até que o longo eixo da coroa dentária coincidisse com o risco central da lente de aumento (Fig. 10A). O número de dentes da engrenagem, rotacionados a partir do seu ponto zero (previamente definido na calibração do dispositivo), corresponde ao valor do ângulo medido.

\section{Definição do valor da angulação da coroa dentária}

As angulações das coroas dentárias são avaliadas em graus positivos ou negativos. A leitura é considerada positiva quando a porção cervical do eixo vestibular da coroa dentária encontra-se mais para distal em relação à porção incisal/oclusal e é considerada negativa quando a porção cervical do eixo vestibular da coroa dentária encontra-se mais para a mesial em relação à porção incisal/oclusal (Fig. 11).

\section{Medição da inclinação dentária}

Para medir a inclinação dentária, utiliza-se a

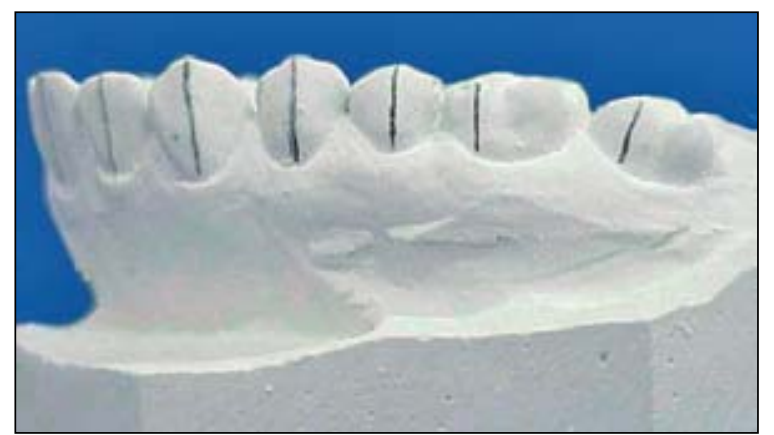

FIGURA 11 - Marcação do longo eixo das coroas dentárias.

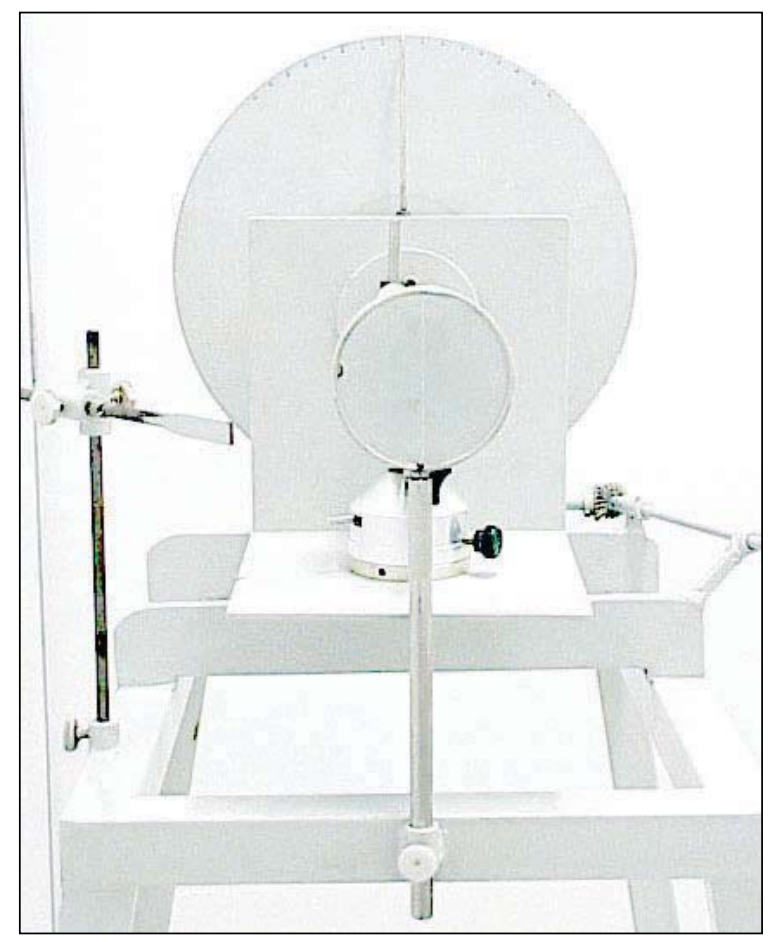

FIGURA 12 - Vista lateral da haste em forma de cruz.

haste em forma de cruz, fixada perpendicularmente à mesa em L e localizada na parte lateral do dispositivo. A ponta da haste é utilizada como plano de referência perpendicular (Fig. 12).

\section{Procedimento de medição da inclinação den- tária}

Após traçar o longo eixo da coroa dentária, o modelo é posicionado na mesa em L, colocando-o em contato com a ponta da haste em forma de cruz (Fig. 13A). A ponta da haste deve tocar o modelo 


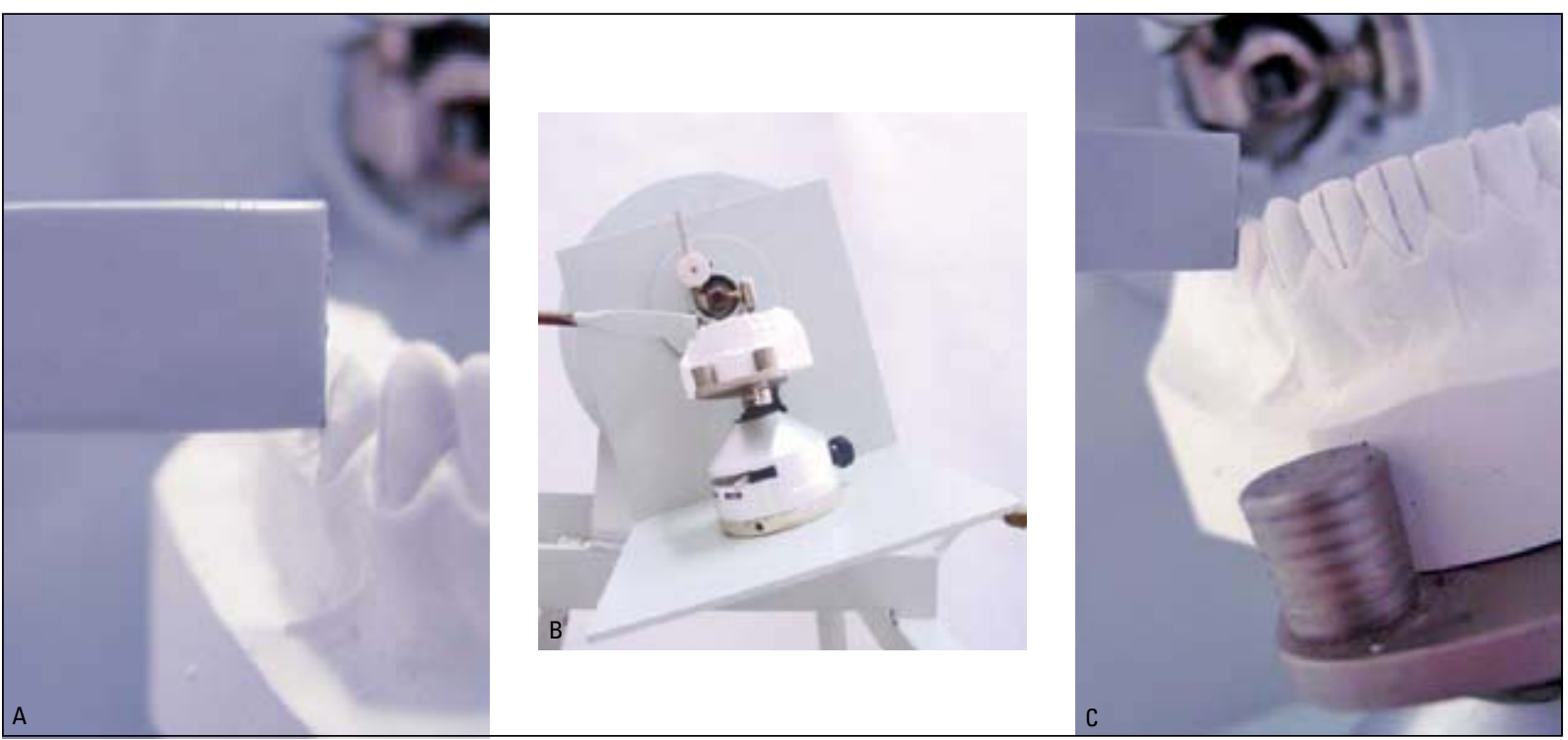

FIGURA 13 - A) Ponta ativa posicionada no centro da coroa dentária. B) Mesa em L rotacionada. C) Ponta paralela e tangente ao longo eixo da coroa dentária.

no ponto médio vertical da coroa dentária, definido por Andrews como ponto EV (eixo vestibular). O valor do ângulo medido é correspondente ao número de dentes da engrenagem rotacionados a partir do ponto zero (Fig. 13B), até que a ponta da haste se posicione paralela e tangente ao longo eixo da coroa dentária (Fig. 13C).

Para testar a utilização e confiabilidade do método, foi realizado um estudo com modelos de gesso, de oclusões normais, de jovens brasileiros, leucodermas e definidas as inclinações e angulações dentárias encontradas nesta amostra da população brasileira com oclusão normal (Quadro 3, 4).

\section{Definição do valor da inclinação da coroa den-} tária

As inclinações dos eixos vestibulares das coroas dentárias são expressas em graus positivos ou negativos. A leitura é considerada positiva quando a porção cervical do eixo vestibular da coroa dentária encon-

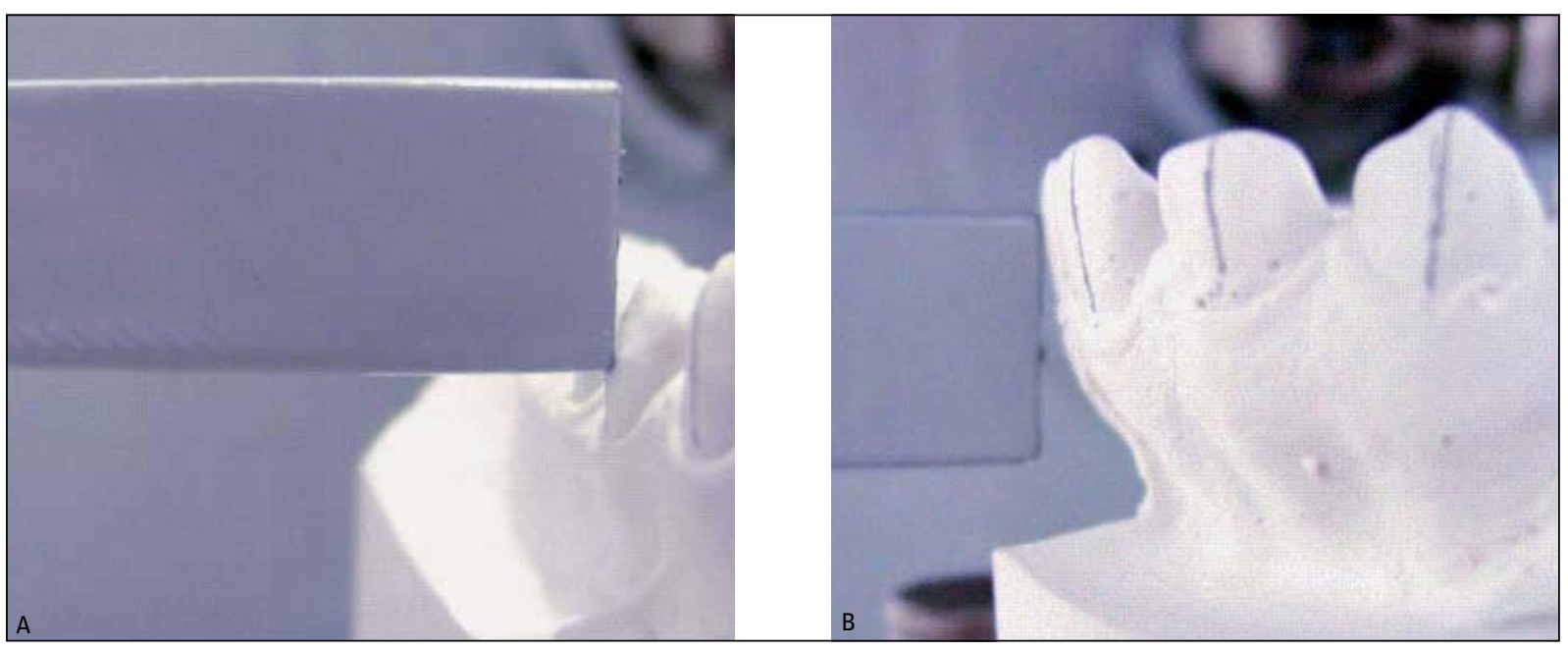

FIGURA 14 - A) Inclinação dentária negativa. B) Inclinação dentária positiva. 


\begin{tabular}{cccccccc}
\hline Dente & $\mathbf{1}$ & $\mathbf{2}$ & $\mathbf{3}$ & $\mathbf{4}$ & $\mathbf{5}$ & $\mathbf{6}$ & $\mathbf{7}$ \\
Angulação & $2,21^{\circ}$ & $6,19^{\circ}$ & $7,13^{\circ}$ & $3,43^{\circ}$ & $4,33^{\circ}$ & $5,55^{\circ}$ & $-0,24^{\circ}$ \\
Inclinação & $5,28^{\circ}$ & $4,99^{\circ}$ & $-6,70^{\circ}$ & $-10,83^{\circ}$ & $-9,95^{\circ}$ & $-10,99^{\circ}$ & $-9,88^{\circ}$ \\
\hline
\end{tabular}

Quadro 3 - Angulações e inclinações dentárias do arco superior, medidas no dispositivo desenvolvido.

\begin{tabular}{cccccccc}
\hline Dente & $\mathbf{1}$ & $\mathbf{2}$ & $\mathbf{3}$ & $\mathbf{4}$ & $\mathbf{5}$ & $\mathbf{6}$ & $\mathbf{7}$ \\
Angulação & $0,03^{\circ}$ & $-0,58^{\circ}$ & $2,43^{\circ}$ & $1,88^{\circ}$ & $3,43^{\circ}$ & $3,39^{\circ}$ & $6,24^{\circ}$ \\
Inclinação & $0,10^{\circ}$ & $-2,03^{\circ}$ & $-10,13^{\circ}$ & $-20,74^{\circ}$ & $-24,38^{\circ}$ & $-28,66^{\circ}$ & $-32,10^{\circ}$ \\
\hline
\end{tabular}

Quadro 4 - Angulações e inclinações dentárias do arco inferior, medidas no dispositivo desenvolvido.

tra-se mais para a lingual em relação à incisal/oclusal, e é considerada negativa quando a porção cervical do eixo vestibular da coroa dentária se encontra mais para vestibular em relação à incisal/oclusal (Fig. 14).

\section{MATERIAL E MÉTODO}

Utilizamos, para a verificação do dispositivo desenvolvido, 60 modelos de gesso de indivíduos com oclusão normal natural. Para a obtenção desta amostra foi analisado um universo de 6.118 indivíduos das escolas de ensino médio e fundamental da região do $\mathrm{ABC}$ paulista. Os critérios pré-estabelecidos para obter um grupo mais homogêneo e criterioso de oclusão normal foram:

- todos os indivíduos deveriam ser brasileiros, leucodermas, com faixa etária compreendida entre 12 e 21 anos de idade.

- nunca terem sido submetidos a qualquer tipo de intervenção ortodôntica.

- deveriam apresentar todos os dentes permanentes na cavidade bucal, com exceção dos terceiros molares.

- a oclusão deveria apresentar, no mínimo, quatro das "Seis Chaves de Oclusão Normal", propostas por Andrews², sendo que a relação inter-arcos ( $1^{\text {a }}$ chave de Andrews) deveria estar obrigatoriamente presente em todos os indivíduos.

- a oclusão foi analisada funcionalmente, através dos movimentos mandibulares, de pro-
Tabela 1 - Valores, em graus, das médias de angulações iniciais (T1) e repetidas (T2) dos dentes superiores, diferença das médias, valor de $t$, valor de $p$ para 0 erro sistemático e valor do erro casual de Dahlberg.

\begin{tabular}{|c|c|c|c|c|c|c|}
\hline \multicolumn{7}{|c|}{ Angulação dos dentes superiores } \\
\hline Variáveis & $\begin{array}{c}\text { Valores } \\
\text { em }_{\bar{X}} \text { T1 }\end{array}$ & $\begin{array}{c}\text { Valores } \\
\text { em T2 }_{\bar{X}}\end{array}$ & $\begin{array}{l}\text { Dif. } \\
\text { das } \\
\text { médias }\end{array}$ & $t$ & $\begin{array}{c}\text { Erro } \\
\text { sistemáti- } \\
\text { co }(p)\end{array}$ & $\begin{array}{c}\text { Erro } \\
\text { cau- } \\
\text { sal }\end{array}$ \\
\hline $\begin{array}{c}\text { Incisivo } \\
\text { Central }\end{array}$ & 3,45 & 4 & $-0,55$ & 2,091 & 0,066 & 0,680 \\
\hline $\begin{array}{l}\text { Incisivo } \\
\text { Lateral }\end{array}$ & 7 & 7,70 & $-0,70$ & 1,709 & 0,122 & 1,000 \\
\hline Canino & 7,15 & 7,9 & $-0,75$ & 1,893 & 0,091 & 0,990 \\
\hline $\begin{array}{l}1^{0} \text { Pré- } \\
\text { molar }\end{array}$ & 4,35 & 4,95 & $-0,6$ & 1,908 & 0,089 & 0,790 \\
\hline $\begin{array}{l}2^{0} \text { Pré- } \\
\text { molar }\end{array}$ & 5,4 & 6,1 & $-0,7$ & 1,210 & 0,257 & 1,322 \\
\hline $1^{\circ}$ Molar & 6,6 & 6,6 & 0 & 0,000 & 1 & 0,612 \\
\hline $2^{\circ}$ Molar & $-1,15$ & $-1,5$ & 0,35 & 1,049 & 0,322 & 0,750 \\
\hline
\end{tabular}

Tabela 2 - Valores, em graus, das médias de angulações iniciais (T1) e repetidas (T2) dos dentes inferiores, diferença das médias, valor de $t$, valor de $p$ para 0 erro sistemático e valor do erro casual de Dahlberg.

\begin{tabular}{|c|c|c|c|c|c|c|}
\hline \multicolumn{7}{|c|}{ Angulação dos dentes inferiores } \\
\hline Variáveis & $\begin{array}{c}\text { Valores } \\
\text { em T1 } \\
\bar{X}\end{array}$ & $\begin{array}{l}\text { Valores } \\
\text { em T2 } \\
\bar{x}\end{array}$ & $\begin{array}{c}\text { Dif. } \\
\text { das } \\
\text { médias }\end{array}$ & $\mathbf{t}$ & $\begin{array}{c}\text { Erro } \\
\text { sistemáti- } \\
\text { co }(p)\end{array}$ & $\begin{array}{c}\text { Erro } \\
\text { ca- } \\
\text { sual }\end{array}$ \\
\hline $\begin{array}{l}\text { Incisivo } \\
\text { Central }\end{array}$ & $-0,05$ & $-0,1$ & 0,05 & 0,361 & 0,726 & 0,300 \\
\hline $\begin{array}{l}\text { Incisivo } \\
\text { Lateral }\end{array}$ & 0,05 & $-0,4$ & 0,45 & 2,077 & 0,068 & 0,560 \\
\hline Canino & 3,6 & 2,85 & 0,75 & 1,330 & 0,216 & 1,310 \\
\hline $\begin{array}{l}1^{0} \text { Pré- } \\
\text { molar }\end{array}$ & 2,1 & 1,95 & 0,15 & 0,580 & 0,576 & 0,560 \\
\hline $\begin{array}{l}2^{0} \text { Pré- } \\
\text { molar }\end{array}$ & 4,2 & 4,65 & $-0,45$ & 0,987 & 0,350 & 1,020 \\
\hline $1^{\circ}$ Molar & 3,85 & 3,85 & 0 & 0,000 & 1 & 1,332 \\
\hline $2^{\circ}$ Molar & 8,45 & 8,2 & 0,25 & 0,510 & 0,622 & 1,054 \\
\hline
\end{tabular}

*Diferença estatisticamente significante $p<0,05$.

trusão e látero-protrusão direita e esquerda, de forma que não deveriam apresentar interferências oclusais.

- sob manipulação mandibular, o fechamento da mandíbula deveria apresentar contatos posteriores simultâneos e bilaterais, apresentando também 
Tabela 3 - Valores, em graus, das médias de inclinações iniciais (T1) e repetidas (T2) dos dentes superiores, diferença das médias, valor de $t$, valor de $p$ para 0 erro sistemático e valor do erro casual de Dahlberg.

\begin{tabular}{|c|c|c|c|c|c|c|}
\hline \multicolumn{7}{|c|}{ Inclinação dos dentes superiores } \\
\hline Variáveis & $\begin{array}{c}\text { Valores } \\
\underset{\bar{X}}{\text { em }} \text { T1 }\end{array}$ & $\begin{array}{c}\text { Valores } \\
\underset{\bar{X}}{\text { em T2 }}\end{array}$ & $\begin{array}{c}\text { Dif. } \\
\text { das } \\
\text { médias }\end{array}$ & $\mathbf{t}$ & $\begin{array}{c}\text { Erro } \\
\text { sistemáti- } \\
\text { co }(p)\end{array}$ & $\begin{array}{c}\text { Erro } \\
\text { ca- } \\
\text { sual }\end{array}$ \\
\hline $\begin{array}{c}\text { Incisivo } \\
\text { Central }\end{array}$ & 6,75 & 7,6 & $-0,85$ & 1,566 & 0,152 & 1,300 \\
\hline $\begin{array}{l}\text { Incisivo } \\
\text { Lateral }\end{array}$ & 6,05 & 6,75 & $-0,7$ & 1,709 & 0,122 & 1,000 \\
\hline Canino & $-7,9$ & $-6,95$ & $-0,95$ & 1,653 & 0,133 & 1,391 \\
\hline $\begin{array}{l}1^{0} \text { Pré- } \\
\text { molar }\end{array}$ & $-13,05$ & $-12,01$ & $-1,04$ & 1,980 & 0,079 & 1,220 \\
\hline $\begin{array}{l}2^{0} \text { Pré- } \\
\text { molar }\end{array}$ & $-9,6$ & $-9,2$ & $-0,4$ & 0,621 & 0,550 & 1,400 \\
\hline $1^{\circ}$ Molar & $-9,55$ & $-8,75$ & $-0,8$ & 1,319 & 0,220 & 1,410 \\
\hline $2^{\circ}$ Molar & $-8,8$ & $-7,9$ & $-0,9$ & 1,890 & 0,091 & 1,193 \\
\hline
\end{tabular}

contatos nos caninos e não haver diferença significante entre a relação cêntrica (RC) e a máxima intercuspidação habitual (MIH). Sessenta (60) indivíduos obedeceram aos critérios propostos, constituindo a amostra desse trabalho, sendo 35 do gênero masculino e 25 do gênero feminino.

\section{RESULTADOS}

Após concluída a pesquisa, determinamos a média da angulação e inclinação de cada coroa dentária, conforme os quadros 3 e 4 . Para obtenção do erro intra-examinador, foram medidos novamente 12 (doze) pares de modelos, ou seja, 20\% (vinte por cento) da amostra, selecionados aleatoriamente, após um período mínimo de 3 (três) meses da primeira medição. A repetição das medidas aconteceu para todos os dentes do modelo, de segundo molar do lado direito até o segundo molar do lado esquerdo, tanto superior, quanto inferior. Aplicou-se o teste $t$ pareado, para verificação do erro sistemático e a fórmula de Dahlberg, para estimar a ordem dos erros casuais.

Para demonstrar a confiabilidade das medidas
Tabela 4 - Valores, em graus, das médias de inclinações iniciais (T1) e repetidas (T2) dos dentes inferiores, diferença das médias, 0 valor de $t$, 0 valor de $p$ para o erro sistemático e valor do erro casual de Dahlberg.

\begin{tabular}{ccccccc}
\hline \multicolumn{7}{c}{ Inclinação dos dentes inferiores } \\
\hline Variáveis & $\begin{array}{c}\text { Valores } \\
\mathbf{e m} \mathbf{T} 1\end{array}$ & $\begin{array}{c}\text { Valores } \\
\mathbf{e m} \text { T2 }\end{array}$ & $\begin{array}{c}\text { Dif. } \\
\text { das } \\
\text { médias }\end{array}$ & $\mathbf{t}$ & $\begin{array}{c}\text { Erro } \\
\text { sistemáti- } \\
\mathbf{c o}(\mathbf{p})\end{array}$ & $\begin{array}{c}\text { Erro } \\
\text { ca- } \\
\text { sual }\end{array}$ \\
\hline $\begin{array}{c}\text { Incisivo } \\
\text { Central }\end{array}$ & 1,6 & 2,4 & $-0,8$ & 1,500 & 0,168 & 1,264 \\
$\begin{array}{c}\text { Incisivo } \\
\text { Lateral }\end{array}$ & $-2,25$ & $-1,7$ & $-0,55$ & 1,316 & 0,221 & 0,970 \\
Canino & -12 & $-11,75$ & $-0,25$ & 2,236 & 0,052 & 0,300 \\
$\mathbf{1}^{\mathbf{0}}$ Pré- & $-22,1$ & $-21,35$ & $-0,75$ & 1,649 & 0,505 & 1,101 \\
molar & & & & & & \\
$\mathbf{2}^{\mathbf{0}}$ Pré- \\
molar & $-25,5$ & $-25,1$ & $-0,4$ & 0,694 & 0,193 & 1,254 \\
$\mathbf{1}^{\mathbf{0}}$ Molar & $-28,75$ & $-28,2$ & $-0,55$ & 1,408 & 0,279 & 0,920 \\
$\mathbf{2}^{\mathbf{0}}$ Molar & $-30,55$ & $-29,95$ & $-0,6$ & 1,152 & 0,091 & 1,183 \\
\hline${ }^{*}$ Diferença estatisticamente significante $\mathrm{p}<0,05$. & &
\end{tabular}

realizadas nos modelos de gesso, em relação à angulação e inclinação da coroas clínicas, nos propusemos a utilizar dois testes estatísticos, como demonstrado nas tabelas.

\section{DISCUSSÃO}

Os modelos de gesso mostram-se como um grande recurso para diagnóstico e planejamento ortodôntico. Porém, seu emprego em pesquisas científicas torna necessária a análise do erro das medidas obtidas, especialmente quando para realizá-las utiliza-se um aparelho novo, nunca antes testado. Trabalhos que mostram a confiabilidade de uma metodologia são importantíssimos, pois avalisam novas pesquisas que apresentam metodologia semelhante. Após a análise das tabelas 1, 2, 3 e 4, observou-se que nenhuma medida obteve diferença estatisticamente significante no erro sistemático. $\mathrm{Na}$ interpretação do erro casual, o maior valor encontrado para o índice de Dahlberg foi de $1,41^{\circ}$, para a medição da inclinação do primeiro molar superior, resultado que pode ser considerado sem implicação clínica, pois a diferenças entre as duas 
médias foi de $0,8^{\circ}$. O dispositivo desenvolvido teve o objetivo de realizar mensurações de angulações e inclinações dentárias, com base numa padronização que eliminasse erros de julgamento subjetivo e de posicionamento dos elementos de leitura, pois temos que considerar que os gabaritos utilizados por Andrews estão sujeitos a pequenas movimentações durante o seu posicionamento, o que compromete a repetição das medidas. Partindo do princípio de que o tratamento ortodôntico deve direcionar o posicionamento final dos dentes de acordo com a oclusão normal e que essa possui variações de angulação e inclinação dentárias, que dependem da origem étnica de cada população, tivemos o propósito de medir as angulações e as inclinações dentárias de uma amostra de oclusão normal, característica da população brasileira, no intuito de contribuir para a maior individualização do tratamento ortodôntico, buscando metas de posicionamento que se assemelhem ao padrão normal do brasileiro.

\section{CONCLUSÃO}

O dispositivo apresentado mostrou-se apto a ser empregado por um mesmo operador em pesquisas utilizando modelos de gesso. Sugere-se que novos estudos sejam realizados para avaliar erros inter-examinadores, comprovando a sua aplicabilidade por diferentes profissionais, o que o tornaria uma ferramenta disponível para o desenvolvimento de trabalhos científicos em âmbito nacional.

\section{Measurement method for the angulation and tipping of dental crowns using plaster models}

\section{Abstract}

This present study aims to present the development of a device specially designed to measure the angulation and tipping of dental crowns. Such device was used in a sample containing 60 subjects, with average age between 12 and 21 yeas of age from both genders. Subjects presented with normal occlusion and had not undergone orthodontic treatment previously. Thus, from this sample, the mean values for the angulation and tipping of dental crowns were established for brazilian subjects.

Key words: Angulation. Tipping. Dental crown.

\section{REFERÊNCIAS}

1. ANDREWS, L. F. Straight-Wire: the concept and appliance. San Diego: L. A. Well, 1989. p. 159

2. ANDREWS, L. F. The six keys to normal occlusion. Am J Orthod St. Louis, v. 62, no. 3, p. 296-309, Sept. 1972

3. HOLDAWAY, R. A. Bracket angulation as applied to the edgewise appliance. Angle Orthod, Appleton, v. 22, no. 4, p. 227-236, Oct. 1952
4. JARABAK, J. R. Development of a treatment plan in the light of one's concept of treatment objectives. Am J Orthod, St. Louis, v. 46, no. 7, p. 481-514, Jul. 1960

5. VADEN, J. L.; DALE, J. G.; KLONTZ, H. A. O aparelho tipo edgewise de Tweed-Merrifield: filosofia, diagnóstico e tratamento. In: GRABER, T. M.; VANARSDALL JR., R. L. Ortodontia: princípios e técnicas atuais. 2. ed., Rio de Janeiro: Guanabara Koogan, 1996. p. 579-635.

\author{
Endereço para correspondência \\ Liliana Maltagliati \\ Rua Salete, 200 s/42 \\ CEP: 02.016-001 - São Paulo/SP \\ E-mail: lilianamaltagliati@hotmail.com
}

